\title{
Strong convergence of the Halpern subgradient extragradient method for solving variational inequalities in Banach spaces
}

Ying Liu

College of Mathematics and Information Science, Hebei University, Baoding, Hebei, 071002, China.

Communicated by S. S. Chang

\begin{abstract}
In this paper, we combine the subgradient extragradient method with the Halpern method for finding a solution of a variational inequality involving a monotone Lipschitz mapping in Banach spaces. By using the generalized projection operator and the Lyapunov functional introduced by Alber, we prove a strong convergence theorem. We also consider the problem of finding a common element of the set of solutions of a variational inequality problem and the set of fixed points of a relatively nonexpansive mapping. Our results improve some well-known results in Banach spaces or Hilbert spaces. (C)2017 all rights reserved.
\end{abstract}

Keywords: Subgradient extragradient method, Halpern method, generalized projection operator, monotone mapping, variational inequality, relatively nonexpansive mapping.

2010 MSC: 47H09, 47H05, 47H06, 47J25, 47J05.

\section{Introduction and preliminaries}

Let $E$ be a real Banach space with norm $\|\cdot\|$, and $E^{*}$ be the dual of $E .\langle x, f\rangle$ denotes the duality pairing of $E$ and $E^{*}$. Suppose that $C$ is a nonempty, closed and convex subset of $E$. In this paper, we study the problem of finding a point $u \in C$ such that

$$
\langle v-u, A u\rangle \geqslant 0, \quad \forall v \in C,
$$

where $A: E \rightarrow E^{*}$ is a single-valued mapping. This problem is called the variational inequality problem. The set of solutions of the variational inequality problem is denoted by $\operatorname{VI}(C, A)$. Variational inequality was firstly introduced by Lions and Stampacchia [15] in 1967. This problem has been intensively considered due to its various applications in operations research, economic equilibrium and engineering design. Various iterative method for solving variational inequality (1.1) have been proposed and analyzed by many authors in Hilbert spaces or Banach spaces when $A$ has monotonicity and Lipschitz continuity or inverse-strong-monotonicity, (see, for example, $[4-8,10-14,16,19-21]$ and the reference therein). An operator $A$ of $C$ into $E^{*}$ is said to be

Email address: 1y_cyh2013@163.com (Ying Liu)

doi:10.22436/jnsa.010.02.06 
(i) monotone if $\langle x-y, A x-A y\rangle \geqslant 0$ for all $x, y \in C$;

(ii) $\alpha$-inverse-strongly-monotone if there exists a positive real number $\alpha$ such that

$$
\langle x-y, A x-A y\rangle \geqslant \alpha\|A x-A y\|^{2}, \quad \forall x, y \in C ;
$$

(iii) L-Lipschitz continuous if there exists a constant $\mathrm{L}>0$ such that

$$
\|A x-A y\| \leqslant L\|x-y\|, \quad \forall x, y \in C .
$$

It is obvious that an $\alpha$-inverse-strongly-monotone mapping is monotone and $\frac{1}{\alpha}$-Lipschitz continuous. But, the converse is not true.

In order to approximate a solution of the variational inequality (1.1), the inverse-strong-monotonicity of $A$ was often assumed (see, for example, $[8,10-12,16,21]$ ).

In the next, we always let $\mathbb{H}$ be a Hilbert space and $\mathbb{N}$ be the set of all positive integers.

In order to relax the inverse-strong-monotonicity of $A$, in a finite dimensional Euclidean space $R^{n}$, Korpelevič [13] introduced the following extragradient method:

$$
x_{1}=x \in C, x_{n+1}=P_{C}\left(x_{n}-\lambda A\left(P_{C}\left(x_{n}-\lambda A x_{n}\right)\right)\right), \forall n \in \mathbb{N},
$$

where A was only supposed to be monotone and Lipschitz continuous. The extragradient method has received great attention by many authors who developed and improved it in various ways, (see, for example, $[4-7,14,19])$.

In the extragradient method, two projections onto a closed and convex subset $\mathrm{C}$ of $\mathbb{H}$ need to be calculated in each iterate. As mentioned in [7], this may affect the efficiency of the method. Therefore, Censor et al. in [7] modified the the extragradient method and proposed the following iterative algorithm:

$$
\left\{\begin{aligned}
x_{0} & \in \mathbb{H} \\
y_{n} & =P_{C}\left(x_{n}-\tau A\left(x_{n}\right)\right), \\
T_{n} & =\left\{w \in \mathbb{H}:\left\langle x_{n}-\tau A\left(x_{n}\right)-y_{n}, w-y_{n}\right\rangle \leqslant 0\right\}, \\
x_{n+1} & =P_{T_{n}}\left(x_{n}-\tau A\left(y_{n}\right)\right) .
\end{aligned}\right.
$$

Method (1.3) replaces the second projection onto the closed and convex subset $C$ in (1.2) with the one onto the subgradient half-space $T_{n}$. So the method (1.3) is called the subgradient extragradient method. We note that, the set $T_{n}$ is a half-space, and hence Algorithm (1.3) is easier to execute than Algorithm (1.2). Under some mild assumptions, Censor et al. in [7] proved the method (1.3) converges weakly to a solution of variational inequality (1.1) in a Hilbert space.

In order to obtain the strong convergence, Kraikaew and Saejung in [14] combined the subgradient extragradient method (1.3) with the Halpern method introduced in [9] and proposed the following iterative algorithm:

$$
\left\{\begin{aligned}
x_{0} & \in \mathbb{H}, \\
y_{n} & =P_{C}\left(x_{n}-\tau A\left(x_{n}\right)\right), \\
T_{n} & =\left\{w \in \mathbb{H}:\left\langle x_{n}-\tau A\left(x_{n}\right)-y_{n}, w-y_{n}\right\rangle \leqslant 0\right\}, \\
x_{n+1} & =\alpha_{n} x_{0}+\left(1-\alpha_{n}\right) P_{T_{n}}\left(x_{n}-\tau A\left(y_{n}\right)\right),
\end{aligned}\right.
$$

where $\left\{\alpha_{n}\right\}$ is a sequence in $[0,1]$ satisfying $\lim _{n \rightarrow \infty} \alpha_{n}=0$ and $\sum_{n=1}^{\infty} \alpha_{n}=\infty$. They proved the method (1.4) converges strongly to a solution of variational inequality (1.1) in a Hilbert space.

We note that, these above results about extragradient method or subgradient extragradient method are all confined in Hilbert spaces. However, many important problems related to practical problems are generally defined in Banach spaces. Hence, it is interesting to propose an iterative algorithm for finding a solution of variational inequality (1.1) in Banach spaces. For example, in 2008, Iiduka and Takahashi in [12] proved the following theorem. 
Theorem 1.1. Let $\mathrm{E}$ be a 2-uniformly convex, uniformly smooth Banach space whose duality mapping $\mathrm{J}$ is weakly sequentially continuous, and C be a nonempty, closed and convex subset of E. Assume that A is an operator of C into $\mathrm{E}^{*}$ that satisfies:

(A1) $\mathrm{A}$ is $\alpha$-inverse-strongly-monotone;

(A2) $\operatorname{VI}(C, A) \neq \emptyset$;

(A3) $\|A y\| \leqslant\|A y-A u\|$ for all $y \in C$ and $u \in V I(C, A)$.

Suppose that $\mathrm{x}_{1}=\mathrm{x} \in \mathrm{C}$ and $\left\{\mathrm{x}_{\mathrm{n}}\right\}$ is given by

$$
x_{n+1}=\Pi_{C} J^{-1}\left(J x_{n}-\lambda_{n} A x_{n}\right),
$$

for every $n=1,2, \ldots$, where $\left\{\lambda_{n}\right\}$ is a sequence of positive numbers. If $\left\{\lambda_{n}\right\}$ is chosen so that $\lambda_{n} \in[a, b]$ for some $\mathrm{a}, \mathrm{b}$ with $0<\mathrm{a}<\mathrm{b}<\mathrm{c}_{1} \alpha$, then the sequence $\left\{x_{n}\right\}$ converges weakly to some element $z \in \mathrm{VI}(\mathrm{C}, \mathrm{A})$, where $\mathrm{c}_{1}$ is the 2-uniformly convexity constant of $\mathrm{E}$. Further $z=\lim _{n \rightarrow \infty} \Pi_{\mathrm{VI}(\mathrm{C}, \mathrm{A})}\left(\mathrm{x}_{\mathrm{n}}\right)$.

We note the following problems:

(P1) The condition (A3) in Theorem 1.1 is not easy to be satisfied.

(P2) Algorithm (1.5) is only restricted to the class of inverse strongly monotone mappings.

(P3) Algorithm (1.5) requires that the Banach space E has the weakly sequentially continuous duality mapping, which is a quite strong hypothesis.

(P4) The sequence $\left\{x_{n}\right\}$ generated by (1.5) converges weakly but not strongly.

In order to solve the problems (P1)-(P4), Nakajo in [20] proposed the following CQ method:

$$
\left\{\begin{aligned}
x_{1} & =x \in E \\
y_{n} & =\Pi_{C} J^{-1}\left(J x_{n}-\lambda_{n} A\left(x_{n}\right)\right), \\
z_{n} & =T y_{n}, \\
C_{n} & =\left\{u \in C: \phi\left(u, z_{n}\right) \leqslant \phi\left(u, x_{n}\right)-\phi\left(y_{n}, x_{n}\right)-2 \lambda_{n}\left\langle y_{n}-u, A x_{n}-A y_{n}\right\rangle\right\}, \\
Q_{n} & =\left\{u \in C:\left\langle x_{n}-u, J x-J x_{n}\right\rangle \geqslant 0\right\}, \\
x_{n+1} & =\Pi_{C_{n}} \cap Q_{n} x,
\end{aligned}\right.
$$

where $E$ is a 2-uniformly convex and uniformly smooth Banach space and $A$ is only supposed to be monotone and Lipschitz continuous. He proved the sequence $\left\{x_{n}\right\}$ generated by (1.6) strongly converges to $\Pi_{D} x$, where $D=V I(C, A) \cap F(T)$ and $T$ is a relatively nonexpansive mapping.

In the Algorithm (1.6), the condition (A3) assumed in Theorem 1.1 is removed and the inverse-strongmonotonicity of $A$ is successfully weakened to monotonicity and Lipschitz continuity. Furthermore, the duality mapping J doesn't need to be weakly sequentially continuous and the sequence $\left\{x_{n}\right\}$ is strong convergence. Therefore, the work done by Nakajo [20] is very meaningful. However, we should also note that Algorithm (1.6) seems to be difficult to use in practice because the computation of the next iterate becomes a subproblem of finding a general minimal distance onto the intersection of two additional closed and convex subsets of a Banach space E. As mentioned in [7], it is not easy to solve a minimal distance onto a general closed and convex set even if in a Hilbert space. This might seriously affect the efficiency of Algorithm (1.6). Therefore, the purpose of this paper is to extend the method (1.4) to Banach spaces. Consequently, we can solve the problems (P1)-(P4) and do not involve this subproblem produced in Algorithm (1.6).

\section{Preliminaries}

Throughout this paper, we always let $E$ be a Banach space, and $E^{*}$ be the dual space of $E .\langle\cdot, \cdot\rangle$ denotes the duality pairing of $E$ and $E^{*}$. When $\left\{x_{n}\right\}$ is a sequence in $E$, we denote the strong convergence of $\left\{x_{n}\right\}$ to $x \in E$ by $x_{n} \rightarrow x$ and the weak convergence by $x_{n} \rightarrow x$. 
Let $\mathrm{U}=\{x \in \mathrm{E}:\|x\|=1\}$. A Banach space $\mathrm{E}$ is said to be strictly convex if for any $x, y \in U$ and $x \neq y$ implies $\left\|\frac{x+y}{2}\right\|<1$. It is also said to be uniformly convex if for each $\epsilon \in(0,2]$, there exists $\delta>0$ such that for any $x, y \in U,\|x-y\| \geqslant \epsilon$ implies $\left\|\frac{x+y}{2}\right\| \leqslant 1-\delta$. It is known that a uniformly convex Banach space is reflexive and strictly convex. And we define a function $\delta:[0,2] \rightarrow[0,1]$ called the modulus of convexity of $E$ as follows:

$$
\delta(\epsilon)=\inf \left\{1-\left\|\frac{x+y}{2}\right\|: x, y \in U,\|x-y\| \geqslant \epsilon\right\} .
$$

Then $E$ is uniformly convex if and only if $\delta(\epsilon)>0$ for all $\epsilon \in(0,2]$. Let $p$ be a fixed real number with $p \geqslant 2$. A Banach space $E$ is said to be $p$-uniformly convex if there exists a constant $c>0$ such that $\delta(\epsilon) \geqslant c \epsilon^{p}$ for all $\epsilon \in[0,2]$. It is obvious that a $p$-uniformly convex Banach space is uniformly convex. For example, see [3] and [12] for more details. A Banach space $E$ is said to be smooth if the $\operatorname{limit}_{\lim } \rightarrow \frac{\|x+t y\|-\|x\|}{t}$ exists for all $x, y \in \mathrm{U}$. It is also said to be uniformly smooth if the limit is attained uniformly for $x, y \in U$. It is well-known that the Hilbert and the Lebesgue $\mathrm{L}^{\mathrm{q}}(1<\mathrm{q} \leqslant 2)$ spaces are 2-uniformly convex, uniformly smooth.

Let $\mathrm{J}: \mathrm{E} \rightarrow 2^{\mathrm{E}^{*}}$ be the normalized duality mapping defined by

$$
\mathrm{Jx}:=\left\{v \in \mathrm{E}^{*}:\langle x, v\rangle=\|v\|^{2}=\|x\|^{2}\right\}, \quad \forall x \in \mathrm{E} .
$$

The following properties of the duality mapping $J$ can be found in [2] :

(i) If $E$ is smooth, then $J$ is single-valued.

(ii) If $\mathrm{E}$ is strictly convex, then $\mathrm{J}$ is one-to-one and strictly monotone.

(iii) If $E$ is uniformly smooth, then $J$ is uniformly norm-to-norm continuous on each bounded subset of E.

(iv) If $\mathrm{E}$ is a smooth, strictly convex, and reflexive Banach space, then J is single-valued, one-to-one, and onto. [2]:

Let $E$ be a smooth Banach space. We know the following Lyapunov functional introduced by Alber

$$
\phi(x, y)=\|x\|^{2}-2\langle x, J y\rangle+\|y\|^{2}, \forall x, y \in E .
$$

Clearly, we have from the definition of $\phi$ that

(B1) $(\|x\|-\|y\|)^{2} \leqslant \phi(y, x) \leqslant(\|x\|+\|y\|)^{2}$;

(B2) $\phi(x, y)=\phi(x, z)+\phi(z, y)+2\langle x-z, J z-J y\rangle$;

(B3) $\phi(x, y)=\langle x, J x-J y\rangle+\langle y-x, J y\rangle \leqslant\|x\|\|J x-J y\|+\|y-x\|\|y\|$.

Remark 2.1. We have from Remark 2.1 in [18] that, if $E$ is a strictly convex and smooth Banach space, then for $x, y \in E, \phi(y, x)=0$ if and only if $x=y$.

Lemma 2.2 ([18]). Let $\mathrm{E}$ be a uniformly convex and smooth Banach space and let $\left\{\mathrm{y}_{\mathrm{n}}\right\},\left\{z_{\mathrm{n}}\right\}$ be two sequences of $\mathrm{E}$. If $\phi\left(y_{n}, z_{n}\right) \rightarrow 0$, and either $\left\{y_{n}\right\}$, or $\left\{z_{n}\right\}$ is bounded, then $y_{n}-z_{n} \rightarrow 0$.

Let $E$ be a reflexive, strictly convex and smooth Banach space. $C$ denotes a nonempty, closed and convex subset of $E$. By Alber [2], for each $x \in E$, there exists a unique element $x_{0} \in C$ (denoted by $\Pi_{C}(x)$ ) such that

$$
\phi\left(x_{0}, x\right)=\min _{y \in C} \phi(y, x) .
$$

The mapping $\Pi_{C}: E \rightarrow C$, defined by $\Pi_{C}(x)=x_{0}$, is called the generalized projection operator from $E$ onto $C$. Moreover, $x_{0}$ is called the generalized projection of $x$. See [1] for some properties of $\Pi_{C}$. In a Hilbert space, $\Pi_{C}=P_{C}$ (the metric projection operator).

Lemma $2.3([12,18])$. Let $\mathrm{C}$ be a nonempty closed and convex subset of a smooth Banach space $\mathrm{E}$ and $\mathrm{x} \in \mathrm{E}$. Then, $x_{0}=\Pi_{C} x$ if and only if

$$
\left\langle x_{0}-\mathrm{y}, \mathrm{Jx}-\mathrm{J} x_{0}\right\rangle \geqslant 0, \quad \forall \mathrm{y} \in \mathrm{C} .
$$


Lemma $2.4([12,18])$. Let $\mathrm{E}$ be a reflexive, strictly convex, and smooth Banach space, let $\mathrm{C}$ be a nonempty closed and convex subset of $\mathrm{E}$ and let $\mathrm{x} \in \mathrm{E}$. Then

$$
\phi\left(y, \Pi_{C} x\right)+\phi\left(\Pi_{C} x, x\right) \leqslant \phi(y, x), \quad \forall y \in C .
$$

Let $C$ be a nonempty closed and convex subset of a smooth, strictly convex and reflexive Banach space $E$ and $T$ be a mapping from $C$ into itself. A point $x \in C$ is said to be a fixed point of $T$ if $T x=x$. We denote the set of fixed points of $T$ by $F(T)$. A point $p \in C$ is said to be an asymptotic fixed point of $T$ if there exists $\left\{x_{n}\right\}$ in $C$ which converges weakly to $p$ and $\lim _{n \rightarrow \infty}\left\|x_{n}-T x_{n}\right\|=0$. We denote the set of all asymptotic fixed points of T by F(T). Following Matsushita and Takahashi [18], a mapping T of $\mathrm{C}$ into itself is said to be relatively nonexpansive (see also [20]) if the following conditions are satisfied:

(i) $\mathrm{F}(\mathrm{T})$ is nonempty;

(ii) $\phi(u, T x) \leqslant \phi(u, x), \forall u \in F(T), x \in C$;

(iii) $\mathrm{F}(\hat{\mathrm{T}})=\mathrm{F}(\mathrm{T})$.

Lemma 2.5 ([18]). Let $\mathrm{E}$ be a strictly convex and smooth Banach space, let $\mathrm{C}$ be a closed convex subset of $\mathrm{E}$, and let $\mathrm{T}$ be a relatively nonexpansive mapping from $\mathrm{C}$ into itself. Then $\mathrm{F}(\mathrm{T})$ is closed and convex.

Let $E$ be a reflexive, strictly convex, smooth Banach space, and $J$ the duality mapping from $E$ into $E^{*}$. Then $J^{-1}$ is also single-valued, one-to-one, surjective, and it is the duality mapping from $E^{*}$ into $E$. We make use of the following mapping $\mathrm{V}$ studied in Alber [2]:

$$
\mathrm{V}\left(x, x^{*}\right)=\|x\|^{2}-2\left\langle x, x^{*}\right\rangle+\left\|x^{*}\right\|^{2},
$$

for all $x \in E$ and $x^{*} \in E^{*}$. In other words, $V\left(x, x^{*}\right)=\phi\left(x, J^{-1}\left(x^{*}\right)\right)$ for all $x \in E$ and $x^{*} \in E^{*}$. For each $x \in E$, the mapping $g$ defined by $g\left(x^{*}\right)=V\left(x, x^{*}\right)$ for all $x^{*} \in E^{*}$ is a continuous, convex function from $E^{*}$ into R.

Lemma 2.6 ([2]). Let $\mathrm{E}$ be a reflexive, strictly convex, smooth Banach space and let $\mathrm{V}$ be as in (2.1). Then

$$
V\left(x, x^{*}\right)+2\left\langle J^{-1}\left(x^{*}\right)-x, y^{*}\right\rangle \leqslant V\left(x, x^{*}+y^{*}\right)
$$

for all $\mathrm{x} \in \mathrm{E}$ and $\mathrm{x}^{*}, \mathrm{y}^{*} \in \mathrm{E}^{*}$.

An operator $A$ of $C$ into $E^{*}$ is said to be hemicontinuous if for all $x, y \in C$, the mapping $f$ of $[0,1]$ into $E^{*}$ defined by $f(t)=A(t x+(1-t) y)$ is continuous with respect to the weak* topology of $E^{*}$.

Lemma 2.7 ([12]). Let $\mathrm{C}$ be a nonempty, closed and convex subset of a Banach space $\mathrm{E}$ and $\mathrm{A}$ a monotone, hemicontinuous operator of $\mathrm{C}$ into $\mathrm{E}^{*}$. Then

$$
\operatorname{VI}(C, A)=\{u \in C:\langle v-u, A v\rangle \geqslant 0 \text { for all } v \in C\} \text {. }
$$

It is obvious from Lemma 2.7 that the set $\mathrm{VI}(\mathrm{C}, \mathrm{A})$ is a closed and convex subset of $\mathrm{C}$.

Lemma 2.8 ([20]). Let $\mathrm{E}$ be a 2-uniformly convex and smooth Banach space. Then, for every $\mathrm{x}, \mathrm{y} \in \mathrm{E}, \phi(\mathrm{x}, \mathrm{y}) \geqslant$ $\mathrm{c}_{1}\|\mathrm{x}-\mathrm{y}\|^{2}$, where $\mathrm{c}_{1}>0$ is the 2-uniformly convexity constant of $\mathrm{E}$.

Lemma 2.9 ([17]). Let $\left\{a_{n}\right\}$ be a sequence of real numbers such that there exists a subsequence $\left\{n_{i}\right\}$ of $\{n\}$ such that $a_{n_{i}}<a_{n_{i}+1}$ for all $i \in \mathbb{N}$. Then there exists a nondecreasing sequence $\left\{m_{k}\right\}$ of $\mathbb{N}$ such that $\lim _{k \rightarrow \infty} m_{k}=\infty$ and the following properties are satisfied by all (sufficiently large) numbers $\mathrm{k} \in \mathbb{N}$ :

$$
a_{m_{k}} \leqslant a_{m_{k}+1} \text { and } a_{k} \leqslant a_{n_{k}+1} .
$$

In fact, $m_{k}=\max \left\{j \leqslant k: a_{j}<a_{j+1}\right\}$. 
Lemma 2.10 ([23]). Let $\left\{a_{n}\right\}$ be a sequence of nonnegative real numbers satisfying the following relation:

$$
a_{n+1} \leqslant\left(1-\alpha_{n}\right) a_{n}+\alpha_{n} \delta_{n}, n \geqslant n_{0}
$$

where $\left\{\alpha_{n}\right\} \subset[0,1]$ and $\left\{\gamma_{n}\right\}$ is a sequence of real numbers satisfying $\sum_{n=1}^{\infty} \alpha_{n}=\infty, \lim _{n \rightarrow \infty} \alpha_{n}=0$, and $\limsup _{n \rightarrow \infty} \gamma_{n} \leqslant 0$. Then $\lim _{n \rightarrow \infty} a_{n}=0$.

Lemma 2.11 ([22]). Let $\mathrm{E}$ be a uniformly convex Banach space and let $\mathrm{r}>0$. Then there exists a continuous strictly increasing convex function $\mathrm{g}:[0,2 \mathrm{r}] \rightarrow \mathrm{R}$ such that $\mathrm{g}(0)=0$ and

$$
\|t x+(1-t) y\|^{2} \leqslant t\|x\|^{2}+(1-t)\|y\|^{2}-t(1-t) g(\|x-y\|),
$$

for all $x, y \in B_{r}$ and $t \in[0,1]$, where $B_{r}=\{z \in B:\|z\| \leqslant r\}$.

\section{The Halpern subgradient extragradient algorithm}

Inspired by Kraikaew and Saejung' results [14], we propose the Algorithm (3.1) to extend the Algorithm (1.4) from Hilbert spaces to Banach spaces and prove a strong convergence theorem (i.e., Theorem 3.5), which is quite different from the scheme proposed by Nakajo [20]. In fact, we do not need to calculate the generalized projections onto the constructible sets $C_{n}$ and $Q_{n}$ as in [20]. It seems to us that we simplify his result with the same conclusion.

In this section, we always assume the following conditions.

(C1) E is a 2-uniformly convex and uniformly smooth Banach space with the 2-uniformly convexity constant $c_{1}$ and $C$ is a nonempty closed convex subset of $E$.

(C2) The mapping $A: E \rightarrow E^{*}$ is monotone and Lipschitz continuous on $C$ with Lipschitz constant $L>0$. (C3) $\operatorname{VI}(C, A) \neq \emptyset$.

Algorithm 3.1. For any $x_{0} \in \mathrm{E}$, we define a sequence $\left\{x_{n}\right\}$ iteratively by

$$
\left\{\begin{aligned}
y_{n} & =\Pi_{C} J^{-1}\left(J x_{n}-\lambda_{n} A\left(x_{n}\right)\right) \\
T_{n} & =\left\{w \in E:\left\langle w-y_{n}, J x_{n}-\lambda_{n} A\left(x_{n}\right)-J y_{n},\right\rangle \leqslant 0\right\} \\
w_{n} & =\Pi_{T_{n}} J^{-1}\left(J x_{n}-\lambda_{n} A\left(y_{n}\right)\right) \\
x_{n+1} & =J^{-1}\left(\alpha_{n} J x_{0}+\left(1-\alpha_{n}\right) J w_{n}\right)
\end{aligned}\right.
$$

where $\left\{\alpha_{n}\right\}$ is a sequence in $[0,1]$ satisfying $\lim _{n \rightarrow \infty} \alpha_{n}=0$ and $\sum_{n=1}^{\infty} \alpha_{n}=\infty$ and $\left\{\lambda_{n}\right\}$ is a sequence in $(0, \infty)$. Remark 3.2. It is obvious that $T_{n}$ is a half-space and $C \subset T_{n}$ for every $n \geqslant 1$.

Lemma 3.3. Let $\left\{x_{n}\right\},\left\{y_{n}\right\}$, and $\left\{w_{n}\right\}$ be the three sequences generated by (3.1). Then, under Conditions (C1)-(C3), we have

$$
\phi\left(u, w_{n}\right) \leqslant \phi\left(u, x_{n}\right)-\left(1-\frac{\lambda_{n} L}{c_{1}}\right)\left[\phi\left(w_{n}, y_{n}\right)+\phi\left(y_{n}, x_{n}\right)\right], \quad \forall u \in V I(C, A) .
$$

In particular, if $\left\{\lambda_{n}\right\}$ satisfies $0<\inf _{n} \geqslant 1 \lambda_{n} \leqslant \sup _{n \geqslant 1} \lambda_{n}<\frac{c_{1}}{L}$, then, $\phi\left(u, w_{n}\right) \leqslant \phi\left(u, x_{n}\right)$.

Proof. Since $w_{n}=\Pi_{T_{n}} J^{-1}\left(J x_{n}-\lambda_{n} A\left(y_{n}\right)\right)$, it follows from Lemma 2.4, (B2), and $\operatorname{VI}(C, A) \subset C \subset T_{n}$ that, for any $u \in \operatorname{VI}(C, A)$,

$$
\begin{aligned}
\phi\left(u, w_{n}\right) \leqslant & \phi\left(u, J^{-1}\left(J x_{n}-\lambda_{n} A\left(y_{n}\right)\right)\right)-\phi\left(w_{n}, J^{-1}\left(J x_{n}-\lambda_{n} A\left(y_{n}\right)\right)\right) \\
= & \phi\left(u, x_{n}\right)+\phi\left(x_{n}, J^{-1}\left(J x_{n}-\lambda_{n} A\left(y_{n}\right)\right)\right)+2\left\langle u-x_{n}, \lambda_{n} A\left(y_{n}\right)\right\rangle \\
& -\phi\left(w_{n}, x_{n}\right)-\phi\left(x_{n}, J^{-1}\left(J x_{n}-\lambda_{n} A\left(y_{n}\right)\right)\right)-2\left\langle w_{n}-x_{n}, \lambda_{n} A\left(y_{n}\right)\right\rangle \\
= & \phi\left(u, x_{n}\right)-\phi\left(w_{n}, x_{n}\right)+2 \lambda_{n}\left\langle u-w_{n}, A\left(y_{n}\right)\right\rangle .
\end{aligned}
$$


Since $u \in \operatorname{VI}(C, A)$ and $A$ is monotone on $C$, we have

$$
\left\langle y_{n}-u, A\left(y_{n}\right)\right\rangle \geqslant 0,
$$

and hence,

$$
\left\langle w_{n}-u, A\left(y_{n}\right)\right\rangle \geqslant\left\langle w_{n}-y_{n}, A\left(y_{n}\right)\right\rangle .
$$

Combining (3.3) with (3.4), we have

$$
\begin{aligned}
\phi\left(u, w_{n}\right) & \leqslant \phi\left(u, x_{n}\right)-\phi\left(w_{n}, x_{n}\right)+2 \lambda_{n}\left\langle y_{n}-w_{n}, A\left(y_{n}\right)\right\rangle \\
& =\phi\left(u, x_{n}\right)-\phi\left(w_{n}, y_{n}\right)-\phi\left(y_{n}, x_{n}\right)-2\left\langle w_{n}-y_{n}, J y_{n}-J x_{n}\right\rangle+2 \lambda_{n}\left\langle y_{n}-w_{n}, A\left(y_{n}\right)\right\rangle \\
& =\phi\left(u, x_{n}\right)-\phi\left(w_{n}, y_{n}\right)-\phi\left(y_{n}, x_{n}\right)+2\left\langle w_{n}-y_{n}, J x_{n}-J y_{n}-\lambda_{n} A\left(y_{n}\right)\right\rangle .
\end{aligned}
$$

By the definition of $T_{n}$, we have

$$
\left\langle w_{n}-y_{n}, J x_{n}-\lambda_{n} A\left(x_{n}\right)-J y_{n},\right\rangle \leqslant 0 .
$$

Thus, it follows from the Lipschitz continuity of A, Lemma 2.8, and Cauchy-Schwarz inequality that

$$
\begin{aligned}
2\left\langle w_{n}-y_{n}, J x_{n}-J y_{n}-\lambda_{n} A\left(y_{n}\right)\right\rangle= & 2\left\langle w_{n}-y_{n}, J x_{n}-J y_{n}-\lambda_{n} A\left(x_{n}\right)\right\rangle \\
& +2 \lambda_{n}\left\langle w_{n}-y_{n}, A\left(x_{n}\right)-A\left(y_{n}\right)\right\rangle \\
\leqslant & 2 \lambda_{n}\left\langle w_{n}-y_{n}, A\left(x_{n}\right)-A\left(y_{n}\right)\right\rangle \\
\leqslant & 2 \lambda_{n} L\left\|w_{n}-y_{n}\right\|\left\|y_{n}-x_{n}\right\| \\
\leqslant & 2 \lambda_{n} L \frac{\sqrt{\phi\left(w_{n}, y_{n}\right)}}{\sqrt{c_{1}}} \frac{\sqrt{\phi\left(y_{n}, x_{n}\right)}}{\sqrt{c_{1}}} \\
\leqslant & \frac{\lambda_{n} L}{c_{1}} \phi\left(w_{n}, y_{n}\right)+\frac{\lambda_{n} L}{c_{1}} \phi\left(y_{n}, x_{n}\right) .
\end{aligned}
$$

Combining (3.6) with (3.5), we have

$$
\begin{aligned}
\phi\left(u, w_{n}\right) & \leqslant \phi\left(u, x_{n}\right)-\phi\left(w_{n}, y_{n}\right)-\phi\left(y_{n}, x_{n}\right)+\frac{\lambda_{n} L}{c_{1}} \phi\left(w_{n}, y_{n}\right)+\frac{\lambda_{n} L}{c_{1}} \phi\left(y_{n}, x_{n}\right) \\
& =\phi\left(u, x_{n}\right)-\left(1-\frac{\lambda_{n} L}{c_{1}}\right)\left[\phi\left(w_{n}, y_{n}\right)+\phi\left(y_{n}, x_{n}\right)\right]
\end{aligned}
$$

which implies that (3.2) holds.

Lemma 3.4. Let $\left\{x_{n}\right\}$ be a bounded sequence in $E$ and $y_{n}=\Pi_{C} J^{-1}\left(J x_{n}-\lambda_{n} A\left(x_{n}\right)\right)$. Assume that $x_{n} \rightarrow \hat{x}$ and $\lim _{n \rightarrow \infty}\left\|x_{n}-y_{n}\right\|=0$. If $\left\{\lambda_{n}\right\}$ satisfies $0<\inf _{n \geqslant 1} \lambda_{n} \leqslant \sup _{n \geqslant 1} \lambda_{n}<\frac{c_{1}}{L}$, then, under conditions (C1)-(C3), $\hat{x} \in \operatorname{VI}(C, A)$.

Proof. Let $x \in C$. Since $y_{n}=\Pi_{C} J^{-1}\left(J x_{n}-\lambda_{n} A\left(x_{n}\right)\right)$, by Lemma 2.3, we have

$$
\left\langle y_{n}-x, J x_{n}-\lambda_{n} A\left(x_{n}\right)-J y_{n}\right\rangle \geqslant 0, \forall n \geqslant 1 \text {. }
$$

Next, we consider

$$
\begin{aligned}
\left\langle x_{n}-x, \lambda_{n} A\left(x_{n}\right)\right\rangle & =\left\langle x_{n}-y_{n}, \lambda_{n} A\left(x_{n}\right)\right\rangle+\left\langle y_{n}-x, \lambda_{n} A\left(x_{n}\right)\right\rangle \\
& =\left\langle x_{n}-y_{n}, \lambda_{n} A\left(x_{n}\right)\right\rangle-\left\langle y_{n}-x, J x_{n}-\lambda_{n} A\left(x_{n}\right)-J y_{n}\right\rangle+\left\langle y_{n}-x_{,} J x_{n}-J y_{n}\right\rangle \\
& \leqslant\left\langle x_{n}-y_{n}, \lambda_{n} A\left(x_{n}\right)\right\rangle+\left\langle y_{n}-x, J x_{n}-J y_{n}\right\rangle \\
& \leqslant \lambda_{n}\left\|A x_{n}\right\|\left\|x_{n}-y_{n}\right\|+\left\|J x_{n}-J y_{n}\right\|\left\|y_{n}-x\right\| .
\end{aligned}
$$


Since $A\left(x_{n}\right)$ is bounded and $\lim _{n \rightarrow \infty}\left\|x_{n}-y_{n}\right\|=0$, we have from (3.7) that $\limsup _{n \rightarrow \infty}\left\langle x_{n}-x, A\left(x_{n}\right)\right\rangle \leqslant$ 0 . It follows from the monotonicity of $A$ that

$$
\langle\hat{x}-x, A(x)\rangle=\limsup _{n \rightarrow \infty}\left\langle x_{n}-x, A(x)\right\rangle \leqslant \limsup _{n \rightarrow \infty}\left\langle x_{n}-x, A\left(x_{n}\right)\right\rangle \leqslant 0, \forall x \in C .
$$

Since $x_{n} \rightarrow \hat{x}$ and $\lim _{n \rightarrow \infty}\left\|x_{n}-y_{n}\right\|=0$, we have $y_{n} \rightarrow \hat{x}$. Since for all $n \geqslant 0, y_{n} \in C$ and $C$ is closed and convex, we have $\hat{x} \in C$. This implies that $\hat{x} \in \mathrm{VI}(C, A)$ by (3.8) and Lemma 2.7.

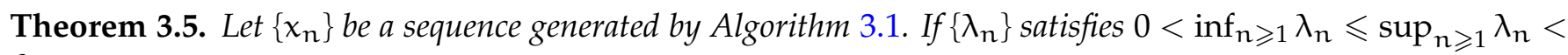
$\frac{\mathrm{c}_{1}}{\mathrm{~L}}$, then, under conditions $(\mathrm{C} 1)-(\mathrm{C} 3), \mathrm{x}_{\mathrm{n}} \rightarrow \Pi_{\mathrm{VI}(\mathrm{C}, \mathrm{A})} \mathrm{x}_{0}$.

Proof. Put $z=\Pi_{\mathrm{VI}(\mathrm{C}, \mathrm{A})} x_{0}$. Since $0<\inf _{\mathrm{n} \geqslant 1} \lambda_{\mathrm{n}} \leqslant \sup _{\mathrm{n} \geqslant 1} \lambda_{\mathrm{n}}<\frac{\mathrm{c}_{1}}{\mathrm{~L}}$, by Lemma 3.3, we have $\phi\left(z, w_{n}\right) \leqslant$ $\phi\left(z, x_{n}\right)$ and hence,

$$
\begin{aligned}
\phi\left(z, x_{n+1}\right) & \leqslant\|z\|^{2}-2\left\langle z, \alpha_{n} J x_{0}+\left(1-\alpha_{n}\right) J w_{n}\right\rangle+\alpha_{n}\left\|x_{0}\right\|^{2}+\left(1-\alpha_{n}\right)\left\|w_{n}\right\|^{2} \\
& =\alpha_{n} \phi\left(z, x_{0}\right)+\left(1-\alpha_{n}\right) \phi\left(z, w_{n}\right) \\
& \leqslant \alpha_{n} \phi\left(z, x_{0}\right)+\left(1-\alpha_{n}\right) \phi\left(z, x_{n}\right) \\
& \leqslant \max \left\{\phi\left(z, x_{0}\right), \phi\left(z, x_{n}\right)\right\} .
\end{aligned}
$$

By induction, we have

$$
\phi\left(z, x_{n}\right) \leqslant \phi\left(z, x_{0}\right) \text { for all } n \geqslant 1 \text {. }
$$

Hence, the sequence $\left\{x_{n}\right\}$ is bounded. It follows from (3.1) and Lemma 2.6 that

$$
\begin{aligned}
\phi\left(z, x_{n+1}\right) & =\phi\left(z, J^{-1}\left(\alpha_{n} J x_{0}+\left(1-\alpha_{n}\right) J w_{n}\right)\right) \\
& =V\left(z, \alpha_{n} J x_{0}+\left(1-\alpha_{n}\right) J w_{n}\right) \\
& \leqslant V\left(z, \alpha_{n} J x_{0}+\left(1-\alpha_{n}\right) J w_{n}-\alpha_{n}\left(J x_{0}-J z\right)\right)+2 \alpha_{n}\left\langle x_{n+1}-z, J x_{0}-J z\right\rangle \\
& =V\left(z, \alpha_{n} J z+\left(1-\alpha_{n}\right) J w_{n}\right)+2 \alpha_{n}\left\langle x_{n+1}-z, J x_{0}-J z\right\rangle \\
& \leqslant \alpha_{n} V(z, J z)+\left(1-\alpha_{n}\right) \mathrm{V}\left(z, J w_{n}\right)+2 \alpha_{n}\left\langle x_{n+1}-z, J x_{0}-J z\right\rangle \\
& =\left(1-\alpha_{n}\right) \phi\left(z, w_{n}\right)+2 \alpha_{n}\left\langle x_{n+1}-z, J x_{0}-J z\right\rangle \\
& \leqslant\left(1-\alpha_{n}\right) \phi\left(z, x_{n}\right)+2 \alpha_{n}\left\langle x_{n+1}-z, J x_{0}-J z\right\rangle .
\end{aligned}
$$

Let us consider the following two cases.

Case 1: There exists an $n_{0} \in \mathbb{N}$ such that $\phi\left(z, x_{n+1}\right) \leqslant \phi\left(z, x_{n}\right)$ for all $n \geqslant n_{0}$. Then $\lim _{n \rightarrow \infty} \phi\left(z, x_{n}\right)$ exists. It follows from (3.9) that

$$
\lim _{n \rightarrow \infty}\left(\phi\left(z, w_{n}\right)-\phi\left(z, x_{n}\right)\right)=0
$$

By Lemma 3.3, we conclude that

$$
\lim _{n \rightarrow \infty} \phi\left(y_{n}, x_{n}\right)=0
$$

We have from Lemma 2.2 that

$$
\lim _{n \rightarrow \infty}\left\|y_{n}-x_{n}\right\|=0
$$

It follows from Lemma 2.3 that $\omega_{w}\left\{x_{n}\right\} \subset \operatorname{VI}(C, A)$, where $\omega_{w}\left\{x_{n}\right\}$ denotes the set of all weak cluster points of the sequence $\left\{x_{n}\right\}$. Passing to a suitable subsequence $\left\{x_{n_{k}}\right\} \subset\left\{x_{n}\right\}$, we assume that

$$
\limsup _{n \rightarrow \infty}\left\langle x_{n+1}-z, J x_{0}-J z\right\rangle=\lim _{k \rightarrow \infty}\left\langle x_{n_{k}}-z, J x_{0}-J z\right\rangle
$$

and $x_{n_{k}} \rightarrow \hat{x}$ for some $\hat{x} \in \operatorname{VI}(C, A)$. Consequently, from Lemma 2.3, we have

$$
\limsup _{n \rightarrow \infty}\left\langle x_{n+1}-z, J x_{0}-J z\right\rangle=\lim _{k \rightarrow \infty}\left\langle x_{n_{k}}-z, J x_{0}-J z\right\rangle=\left\langle\hat{x}-z, J x_{0}-J z\right\rangle \leqslant 0 .
$$

It follows from (3.9) and Lemma 2.10 that $\lim _{n \rightarrow \infty} \phi\left(z, x_{n}\right)=0$, which implies from Lemma 2.2 that $x_{\mathrm{n}} \rightarrow z=\Pi_{\mathrm{VI}(\mathrm{C}, \mathrm{A})} \mathrm{x}_{0}$. 
Case 2: There exists a subsequence $\left\{x_{m_{j}}\right\}$ of $\left\{x_{n}\right\}$ such that

$$
\phi\left(z, x_{m_{j}+1}\right)>\phi\left(z, x_{m_{j}}\right) \text { for all } j \in \mathbb{N} .
$$

From Lemma 2.9, there exists a nondecreasing sequence $\left\{n_{i}\right\}$ of $\mathbb{N}$ such that $\lim _{i \rightarrow \infty} n_{i}=\infty$ and the following inequalities hold for all $i \in \mathbb{N}$ :

$$
\phi\left(z, x_{n_{i}}\right) \leqslant \phi\left(z, x_{n_{i}+1}\right) \text { and } \phi\left(z, x_{i}\right) \leqslant \phi\left(z, x_{n_{i}+1}\right) .
$$

Note that

$$
\phi\left(z, x_{n_{i}}\right) \leqslant \phi\left(z, x_{n_{i}+1}\right) \leqslant \alpha_{n_{i}} \phi\left(z, x_{0}\right)+\left(1-\alpha_{n_{i}}\right) \phi\left(z, w_{n_{i}}\right) \leqslant \alpha_{n_{i}} \phi\left(z, x_{0}\right)+\left(1-\alpha_{n_{i}}\right) \phi\left(z, x_{n_{i}}\right) .
$$

It follows from $\lim _{n \rightarrow \infty} \alpha_{n}=0$ that

$$
\lim _{i \rightarrow \infty}\left[\phi\left(z, w_{n_{i}}\right)-\phi\left(z, x_{n_{i}}\right)\right]=0 .
$$

By discarding the repeated terms of $\left\{n_{i}\right\}$, but still denoted by $\left\{n_{i}\right\}$, we can view $\left\{x_{n_{i}}\right\}$ as a subsequence of $\left\{x_{n}\right\}$. Hence, by Lemmas 3.3, 2.2, and 3.4, we have

$$
\lim _{i \rightarrow \infty}\left\|w_{n_{i}}-y_{n_{i}}\right\|=\lim _{i \rightarrow \infty}\left\|y_{n_{i}}-x_{n_{i}}\right\|=0 \quad \text { and } w_{w}\left\{x_{n_{i}}\right\} \subset V I(C, A) .
$$

Since J is uniformly norm-to-norm continuous on bounded sets, we have

$$
\lim _{i \rightarrow \infty}\left\|J w_{n_{i}}-J y_{n_{i}}\right\|=\lim _{i \rightarrow \infty}\left\|J y_{n_{i}}-J x_{n_{i}}\right\|=0 .
$$

Note that

$$
\begin{aligned}
\left\|J x_{n_{i}+1}-J x_{n_{i}}\right\| & =\left\|\alpha_{n_{i}} J x_{0}+\left(1-\alpha_{n_{i}}\right) J w_{n_{i}}-J x_{n_{i}}\right\| \\
& \leqslant \alpha_{n_{i}}\left\|J x_{0}-J x_{n_{i}}\right\|+\left(1-\alpha_{n_{i}}\right)\left\|J w_{n_{i}}-J x_{n_{i}}\right\| \\
& \leqslant \alpha_{n_{i}}\left\|J x_{0}-J x_{n_{i}}\right\|+\left(1-\alpha_{n_{i}}\right)\left\|J w_{n_{i}}-J y_{n_{i}}\right\|+\left(1-\alpha_{n_{i}}\right)\left\|J y_{n_{i}}-J x_{n_{i}}\right\| .
\end{aligned}
$$

It follows from $\lim _{i \rightarrow \infty} \alpha_{n_{i}}=0$ and (3.11) that

$$
\lim _{i \rightarrow \infty}\left\|J x_{n_{i}+1}-J x_{n_{i}}\right\|=0 .
$$

As proved in the first case, we can conclude that

$$
\limsup _{i \rightarrow \infty}\left\langle x_{n_{i}+1}-z, J x_{0}-J z\right\rangle=\limsup _{i \rightarrow \infty}\left\langle x_{n_{i}}-z, J x_{0}-J z\right\rangle \leqslant 0 .
$$

It follows from (3.9) and (3.10) that

$$
\begin{aligned}
\phi\left(z, x_{n_{i}+1}\right) & \leqslant\left(1-\alpha_{n_{i}}\right) \phi\left(z, x_{n_{i}}\right)+2 \alpha_{n_{i}}\left\langle x_{n_{i}+1}-z, J x_{0}-J z\right\rangle \\
& \leqslant\left(1-\alpha_{n_{i}}\right) \phi\left(z, x_{n_{i}+1}\right)+2 \alpha_{n_{i}}\left\langle x_{n_{i}+1}-z, J x_{0}-J z\right\rangle .
\end{aligned}
$$

Since $\alpha_{n_{i}}>0$, we have that

$$
\phi\left(z, x_{i}\right) \leqslant \phi\left(z, x_{n_{i}+1}\right) \leqslant 2\left\langle x_{n_{i}+1}-z, J x_{0}-J z\right\rangle .
$$

Hence, by (3.12), we have

$$
\limsup _{i \rightarrow \infty} \phi\left(z, x_{i}\right) \leqslant 2 \limsup _{i \rightarrow \infty}\left\langle x_{n_{i}+1}-z, J x_{0}-J z\right\rangle \leqslant 0, \quad \forall i \in \mathbb{N} .
$$

This implies that $x_{i} \rightarrow z=\Pi_{\mathrm{VI}(\mathrm{C}, \mathrm{A})} \mathrm{x}_{0}$, as $i \rightarrow \infty$, by Lemma 2.2. 
Remark 3.6. Theorem 3.5 improves Theorem 1.1 of this paper (i.e., Theorem 3.1 of [12]) in the following senses.

(1) The condition (A3) is removed.

(2) The inverse-strong-monotonicity of $A$ is relaxed to monotonicity and Lipschitz continuity.

(3) The condition that the duality mapping J is weakly sequentially continuous is removed.

(4) The strong convergence of $\left\{x_{n}\right\}$ is obtained.

Remark 3.7. Theorem 3.5 is different from Theorem 3.1 of [20] in the following several aspects.

(1) In Theorem 3.5, $\left\{\lambda_{n}\right\}$ satisfies $0<\inf _{n \in \mathbb{N}} \lambda_{n} \leqslant \sup _{n \in \mathbb{N}} \lambda_{n}<\frac{c_{1}}{L}$, which is weaker than that $\left\{\lambda_{n}\right\}$ satisfies $0<\inf _{n \in \mathbb{N}} \lambda_{n} \leqslant \sup _{n \in \mathbb{N}} \lambda_{n}<\frac{c_{1}}{2 L}$ in Theorem 3.1 of [20].

(2) In Theorem 3.5, we do not need to calculate the intersection of $C_{n}$ and $Q_{n}$ as in Theorem 3.1 of [20].

(3) In Theorem 3.5, we replace the second general projection onto the closed and convex set $C_{n} \cap Q_{n}$ in Theorem 3.1 of [20] with the one onto the half-space $T_{n}$.

Remark 3.8. Remarks 3.6 and 3.7 show that Theorem 3.5 solves the problems (P1)-(P4) mentioned in Section 1 and does not involve a subproblem of finding a point in the intersection of two additional general closed convex subsets of $\mathrm{C}$ as in Theorem 3.1 of [20].

Remark 3.9. If $E=\mathbb{H}$ (the Hilbert space), then $J=I, c_{1}=1$, and $\Pi_{C}=P_{C}$. Taking $E=\mathbb{H}$ and $\lambda_{n} \equiv \tau$ satisfying $\tau \mathrm{L}<1$, then Algorithm (3.1) reduces to Algorithm (1.4) and Theorem 3.5 reduces to Theorem 3.1 of [14]. Therefore, Theorem 3.5 absolutely generalizes Theorem 3.1 of [14] from Hilbert spaces to Banach spaces. Furthermore, we change the parameter from a fixed constant $\tau$ to a changeable sequence $\left\{\lambda_{n}\right\}$.

\section{The Modified subgradient extragradient algorithm}

Inspired by the second main result of Kraikaew et al. [14], we present a modified subgradient extragradient algorithm in Banach spaces for finding a solution of the variational inequality (1.1) which is also a fixed point of a given relatively nonexpansive mapping. Our algorithm is as follows.

For mappings $A, S: E \rightarrow E$ and a closed and convex subset $C$ of $E$, define three iterative sequences $\left\{x_{n}\right\},\left\{y_{n}\right\}$, and $\left\{z_{n}\right\}$ by

$$
\left\{\begin{aligned}
x_{0} & \in E \\
y_{n} & =\Pi_{C} J^{-1}\left(J x_{n}-\lambda_{n} A\left(x_{n}\right)\right), \\
T_{n} & =\left\{w \in E:\left\langle w-y_{n}, J x_{n}-\lambda_{n} A\left(x_{n}\right)-J y_{n},\right\rangle \leqslant 0\right\}, \\
w_{n} & =\Pi_{T_{n}} J^{-1}\left(J x_{n}-\lambda_{n} A\left(y_{n}\right)\right), \\
z_{n} & =J^{-1}\left(\alpha_{n} J x_{0}+\left(1-\alpha_{n}\right) J w_{n}\right), \\
x_{n+1} & =J^{-1}\left(\beta_{n} J x_{n}+\left(1-\beta_{n}\right) J S z_{n}\right),
\end{aligned}\right.
$$

where $\left\{\beta_{n}\right\} \subset[a, b] \subset[0,1]$ for some $a, b \in(0,1)$ and $\left\{\alpha_{n}\right\}$ is a sequence in $[0,1]$ satisfying $\lim _{n \rightarrow \infty} \alpha_{n}=0$ and $\sum_{n=1}^{\infty} \alpha_{n}=\infty$.

Theorem 4.1. Let $\mathrm{E}$ be a 2-uniformly convex and uniformly smooth Banach space with the 2-uniformly convexity constant $\mathrm{c}_{1}$ and $\mathrm{C}$ be a nonempty closed convex subset of $\mathrm{E}$. Let $\mathrm{S}: \mathrm{E} \rightarrow \mathrm{E}$ be a relatively nonexpansive mapping and $\mathrm{A}: \mathrm{E} \rightarrow \mathrm{E}$ a monotone and L-Lipschitz mapping on $\mathrm{C}$. Let $\left\{\lambda_{\mathrm{n}}\right\}$ be a real number sequence satisfying $0<\inf _{n \geqslant 1} \lambda_{n} \leqslant \sup _{n \geqslant 1} \lambda_{n}<\frac{c_{1}}{L}$. Suppose that $\operatorname{VI}(C, A) \cap F(S)$ is nonempty. Let $\left\{x_{n}\right\} \subset E$ be a sequence

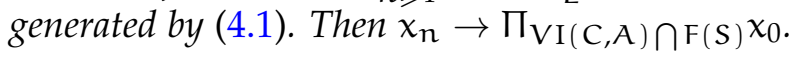

We aligned the proof into several lemmas.

Lemma 4.2. The sequence $\left\{x_{n}\right\}$ is bounded. 
Proof. Let $u \in \operatorname{VI}(C, A) \cap F(S)$. Then we have from Lemma 3.3 that

$$
\begin{aligned}
\phi\left(u, x_{n+1}\right) & \leqslant\|u\|^{2}-2\left\langle u, \beta_{n} J\left(x_{n}\right)+\left(1-\beta_{n}\right) J S\left(z_{n}\right)\right\rangle+\beta_{n}\left\|x_{n}\right\|^{2}+\left(1-\beta_{n}\right)\left\|S z_{n}\right\|^{2} \\
& \leqslant \beta_{n} \phi\left(u, x_{n}\right)+\left(1-\beta_{n}\right) \phi\left(u, z_{n}\right) \\
& \leqslant \beta_{n} \phi\left(u, x_{n}\right)+\left(1-\beta_{n}\right)\left[\alpha_{n} \phi\left(u, x_{0}\right)+\left(1-\alpha_{n}\right) \phi\left(u, w_{n}\right)\right] \\
& \leqslant \beta_{n} \phi\left(u, x_{n}\right)+\left(1-\beta_{n}\right) \alpha_{n} \phi\left(u, x_{0}\right)+\left(1-\beta_{n}\right)\left(1-\alpha_{n}\right) \phi\left(u, x_{n}\right) \\
& =\left[1-\left(1-\beta_{n}\right) \alpha_{n}\right] \phi\left(u, x_{n}\right)+\left(1-\beta_{n}\right) \alpha_{n} \phi\left(u, x_{0}\right) \\
& \leqslant \max \left\{\phi\left(u, x_{n}\right), \phi\left(u, x_{0}\right)\right\} .
\end{aligned}
$$

By induction, $\left\{x_{n}\right\}$ is bounded.

Lemma 4.3. The following inequality holds for all $u \in \operatorname{VI}(C, A) \cap F(S)$ and $n \in \mathbb{N}$,

$$
\phi\left(u, x_{n+1}\right) \leqslant\left[1-\left(1-\beta_{n}\right) \alpha_{n}\right] \phi\left(u, x_{n}\right)+2\left(1-\beta_{n}\right) \alpha_{n}\left\langle z_{n}-u, J x_{0}-J u\right\rangle-\beta_{n}\left(1-\beta_{n}\right) g\left(\left\|J x_{n}-J S z_{n}\right\|\right) .
$$

Proof. Let $u \in \operatorname{VI}(C, A) \cap F(S)$. It follows from Lemmas 2.6, 2.11, and 3.3 that

$$
\begin{aligned}
\phi\left(u, x_{n+1}\right)= & \phi\left(u, J^{-1}\left(\beta_{n} J x_{n}+\left(1-\beta_{n}\right) J S z_{n}\right)\right) \\
\leqslant & \beta_{n} \phi\left(u, x_{n}\right)+\left(1-\beta_{n}\right) \phi\left(u, S z_{n}\right)-\beta_{n}\left(1-\beta_{n}\right) g\left(\left\|J x_{n}-J S z_{n}\right\|\right) \\
\leqslant & \beta_{n} \phi\left(u, x_{n}\right)+\left(1-\beta_{n}\right) \phi\left(u, z_{n}\right)-\beta_{n}\left(1-\beta_{n}\right) g\left(\left\|J x_{n}-J S z_{n}\right\|\right) \\
= & \beta_{n} \phi\left(u, x_{n}\right)+\left(1-\beta_{n}\right) \phi\left(u, J^{-1}\left(\alpha_{n} J x_{0}+\left(1-\alpha_{n}\right) J w_{n}\right)\right)-\beta_{n}\left(1-\beta_{n}\right) g\left(\left\|J x_{n}-J S z_{n}\right\|\right) \\
= & \beta_{n} \phi\left(u, x_{n}\right)-\beta_{n}\left(1-\beta_{n}\right) g\left(\left\|J x_{n}-J S z_{n}\right\|\right)+\left(1-\beta_{n}\right) V\left(u, \alpha_{n} J x_{0}+\left(1-\alpha_{n}\right) J w_{n}\right) \\
\leqslant & \beta_{n} \phi\left(u, x_{n}\right)-\beta_{n}\left(1-\beta_{n}\right) g\left(\left\|J x_{n}-J S z_{n}\right\|\right) \\
& +\left(1-\beta_{n}\right)\left[V\left(u, \alpha_{n} J x_{0}+\left(1-\alpha_{n}\right) J w_{n}-\alpha_{n}\left(J x_{0}-J u\right)\right)+2 \alpha_{n}\left\langle z_{n}-u, J x_{0}-J u\right\rangle\right] \\
= & \beta_{n} \phi\left(u, x_{n}\right)-\beta_{n}\left(1-\beta_{n}\right) g\left(\left\|J x_{n}-J S z_{n}\right\|\right) \\
& +\left(1-\beta_{n}\right)\left[V\left(u, \alpha_{n} J u+\left(1-\alpha_{n}\right) J w_{n}\right)+2 \alpha_{n}\left\langle z_{n}-u, J x_{0}-J u\right\rangle\right] \\
\leqslant & \beta_{n} \phi\left(u, x_{n}\right)-\beta_{n}\left(1-\beta_{n}\right) g\left(\left\|J x_{n}-J S z_{n}\right\|\right) \\
& +\left(1-\beta_{n}\right)\left[\alpha_{n} V(u, J u)+\left(1-\alpha_{n}\right) V\left(u, J w_{n}\right)+2 \alpha_{n}\left\langle z_{n}-u, J x_{0}-J u\right\rangle\right] \\
= & \beta_{n} \phi\left(u, x_{n}\right)-\beta_{n}\left(1-\beta_{n}\right) g\left(\left\|J x_{n}-J S z_{n}\right\|\right)+\left(1-\beta_{n}\right)\left(1-\alpha_{n}\right) \phi\left(u, w_{n}\right) \\
& +2\left(1-\beta_{n}\right) \alpha_{n}\left\langle z_{n}-u, J x_{0}-J u\right\rangle \\
\leqslant & \beta_{n} \phi\left(u, x_{n}\right)-\beta_{n}\left(1-\beta_{n}\right) g\left(\left\|J x_{n}-J S z_{n}\right\|\right)+\left(1-\beta_{n}\right)\left(1-\alpha_{n}\right) \phi\left(u, x_{n}\right) \\
& +2\left(1-\beta_{n}\right) \alpha_{n}\left\langle z_{n}-u, J x_{0}-J u\right\rangle \\
= & {\left[1-\left(1-\beta_{n}\right) \alpha_{n}\right] \phi\left(u, x_{n}\right)+2\left(1-\beta_{n}\right) \alpha_{n}\left\langle z_{n}-u, J x_{0}-J u\right\rangle-\beta_{n}\left(1-\beta_{n}\right) g\left(\left\|J x_{n}-J S z_{n}\right\|\right) . }
\end{aligned}
$$

Lemma 4.4. Let $u \in \operatorname{VI}(C, A) \cap F(S)$. If there exists a subsequence $\left\{x_{n_{k}}\right\}$ of $\left\{x_{n}\right\}$ such that

$$
\liminf _{k \rightarrow \infty}\left(\phi\left(u, x_{n_{k}+1}\right)-\phi\left(u, x_{n_{k}}\right)\right) \geqslant 0,
$$

then $\omega_{w}\left\{x_{n_{k}}\right\} \subset \operatorname{VI}(C, A) \cap F(S)$.

Proof. Since $\lim \inf _{k \rightarrow \infty}\left(\phi\left(u, x_{n_{k}+1}\right)-\phi\left(u, x_{n_{k}}\right)\right) \geqslant 0$, by the construction of $\left\{x_{n+1}\right\}$, the properties of $\phi(\cdot, \cdot)$, and (3.2) for $0<\inf _{n \geqslant 1} \lambda_{n} \leqslant \sup _{n \geqslant 1} \lambda_{n}<\frac{c_{1}}{L}$, we have

$$
\begin{aligned}
0 & \leqslant \liminf _{k \rightarrow \infty}\left(\phi\left(u, x_{n_{k}+1}\right)-\phi\left(u, x_{n_{k}}\right)\right) \\
& \leqslant \liminf _{k \rightarrow \infty}\left(1-\beta_{n_{k}}\right)\left(\alpha_{n_{k}} \phi\left(u, x_{0}\right)+\left(1-\alpha_{n_{k}}\right) \phi\left(u, w_{n_{k}}\right)-\phi\left(u, x_{n_{k}}\right)\right)
\end{aligned}
$$




$$
\begin{aligned}
& =\liminf _{k \rightarrow \infty}\left(1-\beta_{n_{k}}\right)\left(\phi\left(u, w_{n_{k}}\right)-\phi\left(u, x_{n_{k}}\right)\right) \\
& \leqslant(1-a) \liminf _{k \rightarrow \infty}\left(\phi\left(u, w_{n_{k}}\right)-\phi\left(u, x_{n_{k}}\right)\right) \\
& \leqslant(1-a) \limsup _{k \rightarrow \infty}\left(\phi\left(u, w_{n_{k}}\right)-\phi\left(u, x_{n_{k}}\right)\right) \leqslant 0 .
\end{aligned}
$$

Hence,

$$
\lim _{k \rightarrow \infty}\left(\phi\left(u, w_{n_{k}}\right)-\phi\left(u, x_{n_{k}}\right)\right)=0 .
$$

It follows from Lemmas 3.3, 3.4 and 2.2 that

$$
\lim _{k \rightarrow \infty}\left\|x_{n_{k}}-y_{n_{k}}\right\|=0, \lim _{k \rightarrow \infty}\left\|w_{n_{k}}-y_{n_{k}}\right\|=0 \text { and } \omega_{w}\left\{x_{n_{k}}\right\} \subset \operatorname{VI}(C, A) .
$$

Next we show that $\omega_{w}\left\{x_{n_{k}}\right\} \subset F(S)$. By Lemma 4.3, we have

$$
\begin{aligned}
& 0 \leqslant \liminf _{k \rightarrow \infty}\left(\phi\left(u, x_{n_{k}+1}\right)-\phi\left(u, x_{n_{k}}\right)\right) \\
& \leqslant \liminf _{k \rightarrow \infty}\left(-\alpha_{n_{k}}\left(1-\beta_{n_{k}}\right) \phi\left(u, x_{n_{k}}\right)+2 \alpha_{n_{k}}\left(1-\beta_{n_{k}}\right)\left\langle z_{n_{k}}-u, J x_{0}-J u\right\rangle\right. \\
& \left.\quad-\beta_{n_{k}}\left(1-\beta_{n_{k}}\right) g\left(\left\|J x_{n_{k}}-J S z_{n_{k}}\right\|\right)\right) \\
& =-\limsup _{k \rightarrow \infty} \beta_{n_{k}}\left(1-\beta_{n_{k}}\right) g\left(\left\|J x_{n_{k}}-J S z_{n_{k}}\right\|\right) \\
& \leqslant-a(1-b) \limsup _{k \rightarrow \infty} g\left(\left\|J x_{n_{k}}-J S z_{n_{k}}\right\|\right) \leqslant 0 .
\end{aligned}
$$

Hence,

$$
\lim _{k \rightarrow \infty}\left\|J x_{n_{k}}-J S z_{n_{k}}\right\|=0 .
$$

Since $\mathrm{J}^{-1}$ is uniformly norm-to-norm continuous on bounded sets, we have

$$
\lim _{k \rightarrow \infty}\left\|x_{n_{k}}-S z_{n_{k}}\right\|=0 .
$$

Applying (4.1), we have that

$$
J z_{n_{k}}-J x_{n_{k}}=\alpha_{n_{k}}\left(J x_{0}-J x_{n_{k}}\right)+\left(1-\alpha_{n_{k}}\right)\left(J w_{n_{k}}-J x_{n_{k}}\right) .
$$

It follows from (4.2) that

$$
\lim _{k \rightarrow \infty}\left\|w_{n_{k}}-x_{n_{k}}\right\|=0
$$

Since J is also uniformly norm-to-norm continuous on bounded sets, we have that

$$
\lim _{k \rightarrow \infty}\left\|J w_{n_{k}}-J x_{n_{k}}\right\|=0 .
$$

Since $\lim _{k \rightarrow \infty} \alpha_{n_{k}}=0$, it follows from (4.4) and (4.6) that $\lim _{k \rightarrow \infty}\left\|J z_{n_{k}}-J x_{n_{k}}\right\|=0$. Since $J^{-1}$ is uniformly norm-to-norm continuous on bounded sets, we have that

$$
\lim _{k \rightarrow \infty}\left\|z_{n_{k}}-x_{n_{k}}\right\|=0 .
$$

Since $\left\|z_{n_{k}}-S\left(z_{n_{k}}\right)\right\| \leqslant\left\|z_{n_{k}}-x_{n_{k}}\right\|+\left\|x_{n_{k}}-S\left(z_{n_{k}}\right)\right\|$, it follows from (4.3) and (4.7) that

$$
\lim _{k \rightarrow \infty}\left\|z_{n_{k}}-S\left(z_{n_{k}}\right)\right\|=0 .
$$

By (4.8), (4.7) and the definition of the relatively nonexpansive mapping $S$, we infer that $\omega_{w}\left\{x_{n_{k}}\right\}=$ $\omega_{w}\left\{z_{n_{k}}\right\} \subset F(S)$. This and (4.2) imply that $\omega_{w}\left\{x_{n_{k}}\right\} \subset \operatorname{VI}(C, A) \cap F(S)$. 
The next is the proof of Theorem 4.1 .

Proof of Theorem 4.1. Let $z=\Pi_{\operatorname{VI}(C, A) \cap F(S)} x_{0}$. Since $\beta_{n}<1$ for all $n \in \mathbb{N}$, it follows from Lemma 2.3 that

$$
\phi\left(z, x_{n+1}\right) \leqslant\left[1-\left(1-\beta_{n}\right) \alpha_{n}\right] \phi\left(z, x_{n}\right)+2 \alpha_{n}\left(1-\beta_{n}\right)\left\langle z_{n}-z, J x_{0}-J z\right\rangle .
$$

Case 1. There exists an $n_{0} \in \mathbb{N}$ such that $\phi\left(z, x_{n+1}\right) \leqslant \phi\left(z, x_{n}\right)$ for all $n \geqslant n_{0}$. Then $\lim _{n \rightarrow \infty} \phi\left(z, x_{n}\right)$ exists. In particular, $\lim _{n \rightarrow \infty}\left(\phi\left(z, x_{n+1}\right)-\phi\left(z, x_{n}\right)\right)=0$. It follows from Lemma 2.4 and (4.5) that $\omega_{w}\left\{x_{n}\right\} \subset \operatorname{VI}(C, A) \cap F(S)$ and $\lim _{n \rightarrow \infty}\left\|x_{n}-w_{n}\right\|=0$. Since J is uniformly norm-to-norm continuous on bounded sets, we have that

$$
\lim _{n \rightarrow \infty}\left\|J x_{n}-J w_{n}\right\|=0
$$

Since $J z_{n}-J x_{n}=\alpha_{n}\left(J x_{0}-J x_{n}\right)+\left(1-\alpha_{n}\right)\left(J w_{n}-J x_{n}\right)$, it follows from $\lim _{n \rightarrow \infty} \alpha_{n}=0$ and (4.10) that $\lim _{n \rightarrow \infty}\left\|J z_{n}-J x_{n}\right\|=0$. Since $J^{-1}$ is also uniformly norm-to-norm continuous on bounded sets, we have that

$$
\lim _{n \rightarrow \infty}\left\|z_{n}-x_{n}\right\|=0 \text {. }
$$

Hence, $\omega_{w}\left\{x_{n}\right\}=\omega_{w}\left\{z_{n}\right\}$. Since $\left\{x_{n}\right\}$ is bounded, there exists a subsequence $\left\{x_{n_{k}}\right\}$ of $\left\{x_{n}\right\}$ such that $x_{n_{k}} \rightarrow \hat{x}$ and

$$
\lim _{k \rightarrow \infty}\left\langle x_{n_{k}}-z, J x_{0}-J z\right\rangle=\limsup _{n \rightarrow \infty}\left\langle x_{n}-z, J x_{0}-J z\right\rangle=\limsup _{n \rightarrow \infty}\left\langle z_{n}-z, J x_{0}-J z\right\rangle .
$$

Because $\omega_{w}\left\{x_{n}\right\} \subset \operatorname{VI}(C, A) \bigcap F(S)$, it follows from Lemma 2.3 that

$$
\lim _{\mathrm{k} \rightarrow \infty}\left\langle\mathrm{x}_{\mathrm{n}_{\mathrm{k}}}-z, \mathrm{~J} \mathrm{x}_{0}-\mathrm{J} z\right\rangle=\left\langle\hat{\mathrm{x}}-z, \mathrm{~J} \mathrm{x}_{0}-\mathrm{J} z\right\rangle \leqslant 0,
$$

which implies that $\limsup _{n \rightarrow \infty}\left\langle z_{n}-z, J x_{0}-J z\right\rangle \leqslant 0$. By applying Lemma 2.10 to (4.9), we have

$$
\lim _{n \rightarrow \infty} \phi\left(z, x_{n}\right)=0,
$$

that is, $x_{n} \rightarrow z$, as $n \rightarrow \infty$.

Case 2. There exists a subsequence $\left\{x_{m_{j}}\right\}$ of $\left\{x_{n}\right\}$ such that

$$
\phi\left(z, x_{m_{j}}\right)<\phi\left(z, x_{m_{j}+1}\right), \quad \forall j \in \mathbb{N} .
$$

From Lemma 2.9, there exists a nondecreasing sequence $\left\{n_{i}\right\}$ of $\mathbb{N}$ such that $\lim _{i \rightarrow \infty} n_{i}=\infty$ and the following inequalities hold for all $i \in \mathbb{N}$ :

$$
\phi\left(z, x_{n_{i}}\right) \leqslant \phi\left(z, x_{n_{i}+1}\right) \text { and } \phi\left(z, x_{i}\right) \leqslant \phi\left(z, x_{n_{i}+1}\right) .
$$

By discarding the repeated terms of $\left\{n_{i}\right\}$, but still denoted by $\left\{n_{i}\right\}$, we can view $\left\{x_{n_{i}}\right\}$ as a subsequence of $\left\{x_{n}\right\}$. In this case, we have $\liminf _{i \rightarrow \infty}\left(\phi\left(z, x_{n_{i}+1}\right)-\phi\left(z, x_{n_{i}}\right)\right) \geqslant 0$. By Lemma 4.4, we have $\omega_{w}\left\{x_{n_{i}}\right\} \subset$ $\operatorname{VI}(C, A) \bigcap F(S)$ and, by the same argument as in the first case, $\omega_{w}\left\{z_{n_{i}}\right\}=\omega_{w}\left\{x_{n_{i}}\right\}$. It follows from the boundedness of $\left\{x_{n_{i}}\right\}$ that there exists a subsequence $\left\{x_{n_{i_{l}}}\right\}$ of $\left\{x_{n_{i}}\right\}$ such that $x_{n_{i_{l}}} \rightarrow \hat{x}$ and

$$
\begin{aligned}
\limsup _{i \rightarrow \infty}\left\langle x_{n_{i}}-z, J x_{0}-J z\right\rangle & =\limsup _{i \rightarrow \infty}\left\langle z_{n_{i}}-z, J x_{0}-J z\right\rangle \\
& =\lim _{l \rightarrow \infty}\left\langle x_{n_{i_{l}}}-z, J x_{0}-J z\right\rangle=\left\langle\hat{x}-z, J x_{0}-J z\right\rangle \leqslant 0 .
\end{aligned}
$$

It follows from (4.9) and (4.11) that

$$
\begin{aligned}
\operatorname{rcl} \phi\left(z, x_{n_{i}+1}\right) & \leqslant\left[1-\left(1-\beta_{n_{i}}\right) \alpha_{n_{i}}\right] \phi\left(z, x_{n_{i}}\right)+2\left(1-\beta_{n_{i}}\right) \alpha_{n_{i}}\left\langle z_{n_{i}}-z, J x_{0}-J z\right\rangle \\
& \leqslant\left[1-\left(1-\beta_{n_{i}}\right) \alpha_{n_{i}}\right] \phi\left(z, x_{n_{i}+1}\right)+2\left(1-\beta_{n_{i}}\right) \alpha_{n_{i}}\left\langle z_{n_{i}}-z, J x_{0}-J z\right\rangle .
\end{aligned}
$$


In particular, since $\left(1-\beta_{n_{i}}\right) \alpha_{n_{i}}>0$ for all $i \in \mathbb{N}$, we have

$$
\phi\left(z, x_{i}\right) \leqslant \phi\left(z, x_{n_{i}+1}\right) \leqslant 2\left\langle z_{n_{i}}-z, J x_{0}-J z\right\rangle .
$$

Consequently, it follows from (4.12) that

$$
\limsup _{i \rightarrow \infty} \phi\left(z, x_{i}\right) \leqslant \limsup _{i \rightarrow \infty} 2\left\langle z_{n_{i}}-z, J x_{0}-J z\right\rangle \leqslant 0 .
$$

Therefore $x_{i} \rightarrow z$.

Remark 4.5. If $\mathrm{E}=\mathbb{H}$, then a relatively nonexpansive mapping $S$ reduces to a quasi-nonexpansive mapping $S$ which satisfies $I-S$ is demiclosed at zero. Hence, taking $E=\mathbb{H}$ and $\lambda_{n} \equiv \tau$ satisfying $\tau L<1$, then Theorem 4.1 reduces to Theorem 4.1 of [14]. Therefore, Theorem 4.1 absolutely generalizes Theorem 4.1 of [14] from Hilbert spaces to Banach spaces. Furthermore, we change the parameter from a fixed constant $\tau$ to a changeable sequence $\left\{\lambda_{n}\right\}$.

We next introduce another algorithm, which is a slight modification of Algorithm (4.1) and includes Algorithm (4.1) when $S$ is the identity mapping. Since the proof of this result is very similar to that of Theorem 4.1, we leave the proof for the reader to verify.

Theorem 4.6. Let $\left\{x_{n}\right\} \subset \mathrm{E}$ be a sequence generated by

$$
\left\{\begin{aligned}
x_{0} & \in E \\
y_{n} & =\Pi_{C} J^{-1}\left(J x_{n}-\lambda_{n} A\left(x_{n}\right)\right), \\
T_{n} & =\left\{w \in E:\left\langle w-y_{n}, J x_{n}-\lambda_{n} A\left(x_{n}\right)-J y_{n},\right\rangle \leqslant 0\right\} \\
w_{n} & =\Pi_{T_{n}} J^{-1}\left(J x_{n}-\lambda_{n} A\left(y_{n}\right)\right) \\
z_{n} & =J^{-1}\left(\alpha_{n} J x_{0}+\left(1-\alpha_{n}\right) J w_{n}\right), \\
x_{n+1} & =J^{-1}\left(\beta_{n} J z_{n}+\left(1-\beta_{n}\right) J S z_{n}\right) .
\end{aligned}\right.
$$

Then under the same conditions as Theorem $4.1, x_{n} \rightarrow \Pi_{V I(C, A) \cap F(S)} x_{0}$.

\section{Conclusions}

The subgradient extragradient method was firstly introduced by Censor et al. [7] which provides a weak convergence theorem for variational inequalities of monotone and Lipschitz continuous operators in Hilbert spaces. Subsequently, Kraikaew and Saejung [14] modified this method to obtain strong convergence by means of Halpern method [9] in Hilbert spaces. In this paper, we generalized the results of [14] from Hilbert spaces to Banach spaces. Consequently, we improve and extend the corresponding results in [2,5-7]. Furthermore, our results are different from the ones studied in [7] as described in Remarks 3.7 and 3.8 .

\section{Acknowledgment}

This work was financially supported by the National Natural Science Foundation of China (11401157).

\section{References}

[1] Y. Alber, S. Guerre-Delabriere, On the projection methods for fixed point problems, Analysis (Munich), 21 (2001), 17-39. 2

[2] Ya. I. Al'ber, S. Reich, An iterative method for solving a class of nonlinear operator equations in Banach spaces, Panamer. Math. J., 4 (1994), 39-54. 2, 2, 2, 2.6, 5 
[3] K. Ball, E. A. Carlen, E. H. Lieb, Sharp uniform convexity and smoothness inequalities for trace norms, Invent. Math., 115 (1994), 463-482. 2

[4] N. Buong, Strong convergence theorem of an iterative method for variational inequalities and fixed point problems in Hilbert spaces, Appl. Math. Comput., 217 (2010), 322-329. 1, 1

[5] L.-C. Ceng, N. Hadjisavvas, N.-C. Wong, Strong convergence theorem by a hybrid extragradient-like approximation method for variational inequalities and fixed point problems, J. Global Optim., 46 (2010), 635-646. 5

[6] Y. Censor, A. Gibali, S. Reich, Strong convergence of subgradient extragradient methods for the variational inequality problem in Hilbert space, Optim. Methods Softw., 26 (2011), 827-845.

[7] Y. Censor, A. Gibali, S. Reich, The subgradient extragradient method for solving variational inequalities in Hilbert space, J. Optim. Theory Appl., 148 (2011), 318-335. 1, 1, 1, 5

[8] J.-M. Chen, L.-J. Zhang, T.-G. Fan, Viscosity approximation methods for nonexpansive mappings and monotone mappings, J. Math. Anal. Appl., 334 (2007), 1450-1461. 1

[9] B. Halpern, Fixed points of nonexpanding maps, Bull. Amer. Math. Soc., 73 (1967), 957-961. 1, 5

[10] H. Iiduka, W. Takahashi, Strong convergence theorems for nonexpansive nonself-mappings and inverse-strongly-monotone mappings, J. Convex Anal., 11 (2004), 69-79. 1

[11] H. Iiduka, W. Takahashi, Strong convergence theorems for nonexpansive mappings and inverse-strongly monotone mappings, Nonlinear Anal., 61 (2005), 341-350.

[12] H. Iiduka, W. Takahashi, Weak convergence of a projection algorithm for variational inequalities in a Banach space, J. Math. Anal. Appl., 339 (2008), 668-679. 1, 1, 2, 2.3, 2.4, 2.7, 3.6

[13] G. M. Korpelevič, An extragradient method for finding saddle points and for other problems, (Russian) Ékonom. i Mat. Metody, 12 (1976), 747-756. 1

[14] R. Kraikaew, S. Saejung, Strong convergence of the Halpern subgradient extragradient method for solving variational inequalities in Hilbert spaces, J. Optim. Theory Appl., 163 (2014), 399-412. 1, 1, 1, 3, 3.9, 4, 4.5, 5

[15] J.-L. Lions, G. Stampacchia, Variational inequalities, Comm. Pure Appl. Math., 20 (1967), 493-517. 1

[16] Y. Liu, Strong convergence theorem for relatively nonexpansive mapping and inverse-strongly-monotone mapping in a Banach space, Appl. Math. Mech. (English Ed.), 30 (2009), 925-932. 1

[17] P.-E. Maingé, Strong convergence of projected subgradient methods for nonsmooth and nonstrictly convex minimization, Set-Valued Anal., 16 (2008), 899-912. 2.9

[18] S.-Y. Matsushita, W. Takahashi, A strong convergence theorem for relatively nonexpansive mappings in a Banach space, J. Approx. Theory, 134 (2005), 257-266. 2.1, 2.2, 2.3, 2.4, 2, 2.5

[19] N. Nadezhkina, W. Takahashi, Strong convergence theorem by a hybrid method for nonexpansive mappings and Lipschitzcontinuous monotone mappings, SIAM J. Optim., 16 (2006), 1230-1241. 1, 1

[20] K. Nakajo, Strong convergence for gradient projection method and relatively nonexpansive mappings in Banach spaces, Appl. Math. Comput., 271 (2015), 251-258. 1, 1, 2, 2.8, 3, 3.7, 3.8

[21] W. Takahashi, M. Toyoda, Weak convergence theorems for nonexpansive mappings and monotone mappings, J. Optim. Theory Appl., 118 (2003), 417-428. 1

[22] H.-K. Xu, Inequalities in Banach spaces with applications, Nonlinear Anal., 16 (1991), 1127-1138. 2.11

[23] H.-K. Xu, Another control condition in an iterative method for nonexpansive mappings, Bull. Austral. Math. Soc., 65 (2002), 109-113. 2.10 